\title{
The Mechanism of Phillyrin from the Leaves of Forsythia suspensa for Improving Insulin Resistance
}

\author{
Xiaoqing Xu, ${ }^{1,2}$ Fatma S. A. Saadeldeen, ${ }^{1,3}$ Lanting Xu, ${ }^{1}$ Yingying Zhao, ${ }^{1}$ Jinfeng Wei, \\ Hui-Min David Wang $\mathbb{D}^{4},{ }^{4}$ Zhenhua Liu $\mathbb{D}^{1},{ }^{1,2}$ and Wenyi Kang $\mathbb{D}^{1,2}$ \\ ${ }^{1}$ National R \& D Center for Edible Fungus Processing Technology, Henan University, Kaifeng 475004, China \\ ${ }^{2}$ Joint International Research Laboratory of Food \& Medicine Resource Function, Henan Province, Kaifeng 475004, China \\ ${ }^{3}$ Medicinal and Aromatic Plant Research Department, Horticulture Research Institute, Agricultural Research Centre, \\ Cairo 12611, Egypt \\ ${ }^{4}$ Graduate Institute of Biomedical Engineering, National Chung Hsing University, Taichung City 402, Taiwan
}

Correspondence should be addressed to Zhenhua Liu; liuzhenhua623@163.com and Wenyi Kang; kangweny@hotmail.com

Xiaoqing Xu and Fatma S. A. Saadeldeen contributed equally to this work.

Received 28 February 2019; Revised 14 May 2019; Accepted 9 June 2019; Published 2 July 2019

Academic Editor: Brant R. Burkhardt

Copyright (C) 2019 Xiaoqing Xu et al. This is an open access article distributed under the Creative Commons Attribution License, which permits unrestricted use, distribution, and reproduction in any medium, provided the original work is properly cited.

Three lignans, phillyrin, forsythia ester A, and rosin- $\beta$-D-furan glucose, were isolated from Forsythia suspensa which is a famous Traditional Chinese Medicine used for clearing heat and detoxifying, reducing swelling and dispersing knot, and dispersing wind heat. In this study, the effects of phillyrin, forsythia ester A, and rosin- $\beta$-D-furan glucose on insulin resistance of 3T3-L1 adipocytes were investigated by the method of glucose oxidase-peroxidase (GOD-POD) and the mechanism was assayed by the method of western blot. The results indicated that phillyrin, forsythia ester $A$, and rosin- $\beta$-D-furan glucose could improve the glucose uptake in 3T3-L1 adipocytes under insulin resistance (IR). Among them, phillyrin showed significant activity in increasing glucose consumption at the concentrations of $100 \mu \mathrm{M}$ and $200 \mu \mathrm{M}(P<0.001)$. The mechanism of improving insulin resistance may be that phillyrin could raise the protein phosphorylation of IRS-1 and Akt and the expression levels of GLUT4 protein.

\section{Introduction}

Type 2 Diabetes (T2DM) is characterized by insulin resistance (IR) and destruction of $\beta$ cells in pancreas [1-3]. IR refers to the reduction of insulin in regulating glucose homeostasis in its main target tissues (such as skeletal muscle, fat, and liver) $[4,5]$. It is not only an important pathophysiological mechanism of the onset of T2DM, but also the common basis of atherosclerosis, metabolic syndrome, and other diseases $[6,7]$. Therefore, how to improve the sensitivity of insulin has become a key goal in the treatment of T2DM.

Insulin as a key drug for the treatment of T2DM binds to the corresponding receptor of the target cell and causes the phosphorylation of tyrosine residue and then activates $\beta$ subunits of tyrosine protein kinase. Then, tyrosine protein kinase is activated to make the target cell substrates such as
"IRS" and "SHC" phosphorylate tyrosine residues. Also, tyrosine protein kinase plays an important role in insulin receptor signaling $[8,9]$. These events finally activate insulin signaling pathway, including insulin receptor substrate 1-Rat sarcomamitogen activation protein kinase (IRS-RaS-MAPK) and insulin receptor substrate 1-phosphatidylinositol-3 kinaseprotein kinase B (IRS-1/PI3K/Akt) [10]. The former mainly regulates cell growth and apoptosis. The latter participates in metabolic effects, like glucose transport and utilization, glycogen synthesis, and the like, which plays a very important role in the development of IR. And it is a very important signaling pathway in the study of T2DM. In the insulin signaling pathway, insulin binds to InsR, which is phosphorylated by its own tyrosinase to activate IRS-1, and the phosphorylated IRS binds the regulatory subunit P85 of phosphatidylinositol 3kinase (PI-3K) $[11,12]$, further activating its catalytic subunit 
P110 [13, 14]. The IRS-1 protein is the main substrate of insulin receptor, and IRS-1 binds to the Tyr sequence, which is phosphorylated by the insulin receptor molecule through its $\mathrm{SH} 2$ region, thereby triggering further phosphorylation [15, 16]. Activated PI3K phosphorylates serine-threonine kinase (Akt) $[17,18]$, and phosphorylated Akt stimulates GLUT4 in vesicles transferring from cytoplasm to cell membrane, thus promoting the uptake and utilization of glucose to various tissues $[9,19,20]$. Therefore, it is important to reduce IR and promote glucose metabolism for T2DM.

Forsythia suspensa is a famous Traditional Chinese Medicine with the functions of clearing heat and detoxifying, reducing swelling and dispersing knot, and dispersing wind heat $[21,22]$. F. suspensa also has many pharmacological activities, such as antioxidation, anti-infection, antibacterial, antiendotoxin, heart protection, anti-inflammatory, liver protection, antivirus, and antifatigue [23-25]. Our previous researches showed that the ethyl acetate extract of $F$. suspensa and its chemical components had the effect of lowering blood lipid [26]. The main active ingredients of F. suspensa were phillyrin, oleanolic acid, forsythia lipid, etc. [21]. However, there have been no reports on the mechanism of the active ingredients of F. suspensa to improve IR. Therefore, mouse embryonic preadipocytes 3T3-L1 adipocytes were used to investigate the activities and their mechanisms of phillyrin, forsythia ester A (FEA), and rosin- $\beta$-D-furan glucose (RFG) from the leaves of F. suspensa for improving insulin resistance.

\section{Materials and Methods}

2.1. Cell Culture. Mouse 3T3-L1 preadipocyte cells (TCSC Culture Collection) were grown in high glucose $(4.5 \mathrm{mM})$ DMEM (glutamine, $10 \mu \mathrm{g} / \mathrm{mL}$ penicillin streptomycin, 10 $\mathrm{U} / \mathrm{mL}$, pyruvic acid, and ammonium) with $10 \% \mathrm{FBS}$ at $37^{\circ} \mathrm{C}$ in $5 \% \mathrm{CO}_{2}$ atmosphere and cell fusion rate of $70 \% \sim 80 \%$, extending the ratio of 1:3 [27].

2.2. Cell Viability Assay. 3T3-L1 preadipocytes were seeded into 96-well plates (cell density was $5 \times 10^{3}$ cells per well) and cultured for $24 \mathrm{~h}$. Cells were treated with different concentrations of phillyrin, FEA, and RFG (concentration of $400,200,100,50,25,12.5$, and $6.25 \mu \mathrm{M}$ ) for $48 \mathrm{~h}$; after that, MTT (3-(4,5-dimethylthiazol-2-yl)-2,5-diphenyltetrazolium bromide) $0.5 \mathrm{mg} / \mathrm{mL}$ was added; then cells were maintained in an incubator at $37^{\circ} \mathrm{C}$ for $4 \mathrm{~h}$. After discarding the supernatant, the insoluble formazan crystals were dissolved by $100 \mu \mathrm{L}$ dimethyl sulfoxide (DMSO) to each well, and the plates were shaken for $10 \mathrm{~min}$. Absorbance was measured by a microplate reader (Thermo Fisher, Finland) at $490 \mathrm{~nm}$. Control cells were arbitrarily assigned $100 \%$ viability.

\subsection{Determination of Insulin Resistance to Adipocyte Glucose} Uptake. The cells were cultured in 96-well plates (cell density was $2 \times 10^{4}$ ), and the medium was changed 24 hours later. At this time, cell contact inhibition was observed. After the inhibition of cell contact, medium was changed to 10\% FBS DMEM supplemented with $0.5 \mathrm{mM} 3$-isobutyl-1methylxanthine (IBMX), $1 \mathrm{mM}$ dexamethasone (Dex), and 10 $\mu \mathrm{g} / \mathrm{mL}$ insulin. 3 days later, the medium was replaced with
DMEM supplemented with 15\% FBS and insulin (10 mg/L) and cultured for 2 days, and then the medium was changed to normal culture medium and cultured for another for 4 days. After inducing differentiation into mature adipocytes, 1 $\mu \mathrm{M}$ Dex was used for modeling for $72 \mathrm{~h}$. After that, $10 \mathrm{~mol} / \mathrm{L}$ sodium orthovanadate was used as positive control drug and different concentrations of phillyrin, FEA, and RFG were cultured for $48 \mathrm{~h}$. The method of glucose oxidase-peroxidase (GOD-POD) was used to determine the level of glucose in the cell supernatant by a glucose assay kit (Shanghai Rongsheng Biotech Co.) according to the manufacturer's instructions.

2.4. Western Blot Analysis. Cells harvested with different concentrations of phillyrin for $48 \mathrm{~h}$ were collected and lysed on ice for $30 \mathrm{~min}$ in a mixture containing RadioImmunoprecipitation Assay (RIPA), phenylmethane sulfonyl fluoride (PMSF), and phosphatase inhibitors. The lysate was centrifuged at $12000 \mathrm{rpm}$ for $10 \mathrm{~min}$ at $4^{\circ} \mathrm{C}$. Protein concentration was measured by a BCA protein assay kit (Solarbio Science \& Technology Co., Ltd.). After quantitative protein sample, it was added to $5 \mathrm{x}$ loading buffer, under $100^{\circ} \mathrm{C}$ high temperature degeneration. Protein samples at the same amount $(50 / 70 \mu \mathrm{g})$ were separated on $10 \%$ SDS-polyacrylamide gel. Proteins were transferred onto polyvinylidene fluoride (PVDF) membranes (0.2 $\mu \mathrm{M}, \mathrm{EMD}$ Millipore, Billerica, MA, USA), which were blocked in 5\% nonfat dry milk for $2 \mathrm{~h}$. The membrane added to specific primary antibodies was diluted in TBST overnight at $4^{\circ} \mathrm{C}$. Then, it was incubated with horseradish peroxidase conjugated secondary antibody for $1 \mathrm{~h}$. After wash, the protein of interest was identified by an ECL Plus Ultrasensitive Liquid.

2.5. Statistical Analysis. The experimental results were expressed by arithmetic means \pm standard deviation (SD), and the numerical statistics were analyzed by SPSS 19.0 software one-way analysis of variance. $P \leq 0.05$ was considered to be statistically significant. All bar images were analyzed by GraphPad Prism 6.0 software.

\section{Results}

3.1. Effects of Phillyrin, FEA, and RFG on 3T3-L1 Cell Viability. The cytotoxic effects of phillyrin, FEA, and RFG on cell viability were evaluated by MTT assay. Phillyrin, FEA, and RFG all showed no cytotoxicity at concentrations less than $400 \mu \mathrm{M}$ (Figure 1).

3.2. Effects of Phillyrin, FEA, and RFG on IR in Adipocyte Glucose Depletion. The glucose content of the supernatant was measured after $48 \mathrm{~h}$ of exposure to phillyrin, FEA, and RFG at different concentrations with the glucose oxidase kit. The model exhibited a significant difference $(P<0.001)$ compared with the control group. Sodium orthovanadate (Van) could significantly promote IR in adipocytes glucose consumption $(P<0.001)$ compared with the model group. Phillyrin could significantly promote IR in adipocytes glucose consumption at the concentrations of 200 and $100 \mu \mathrm{M}$ $(P<0.001)$ (Figure $2(\mathrm{a}))$. FEA could promote the glucose uptake of IR 3T3-L1 adipocytes at the concentrations of 200, 


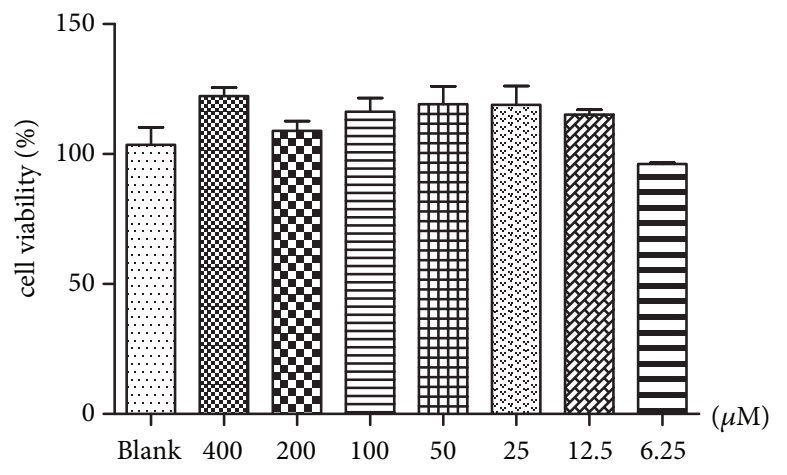

(a)

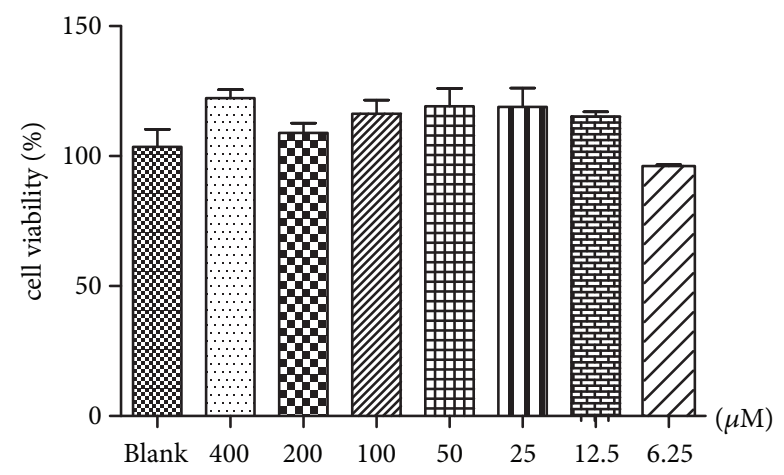

(b)

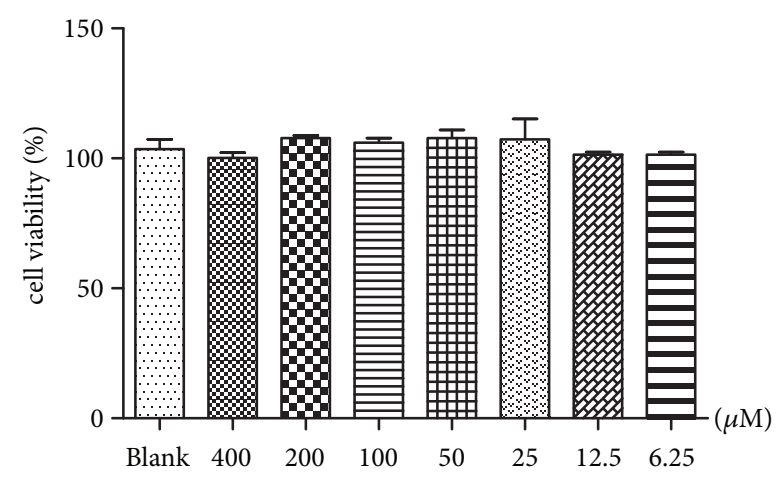

(c)

FIGURE 1: (a) Effect of phillyrin on the viability of 3T3-L1 adipocytes. (b) Effect of FEA on the viability of 3T3-L1 adipocytes. (c) Effect of RFG on the viability of 3T3-L1 adipocytes. Data are presented as means $\pm \mathrm{SD}, n=6$.

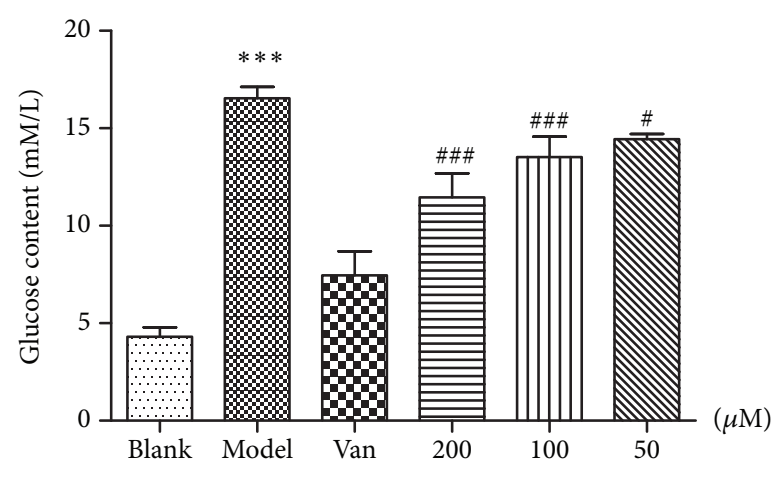

(a)

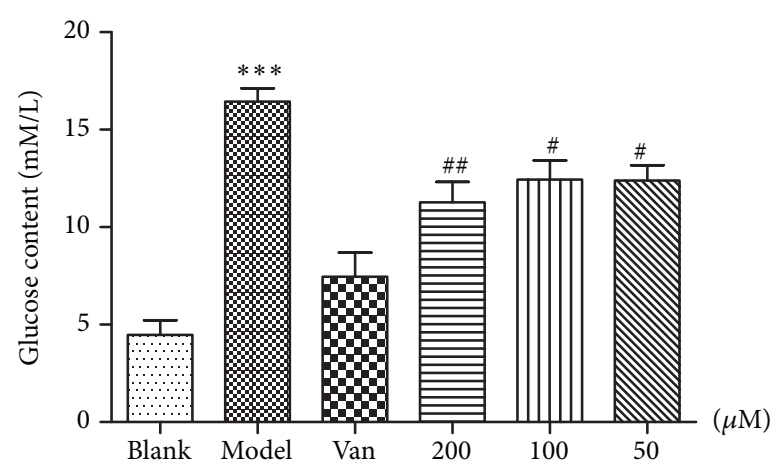

(b)

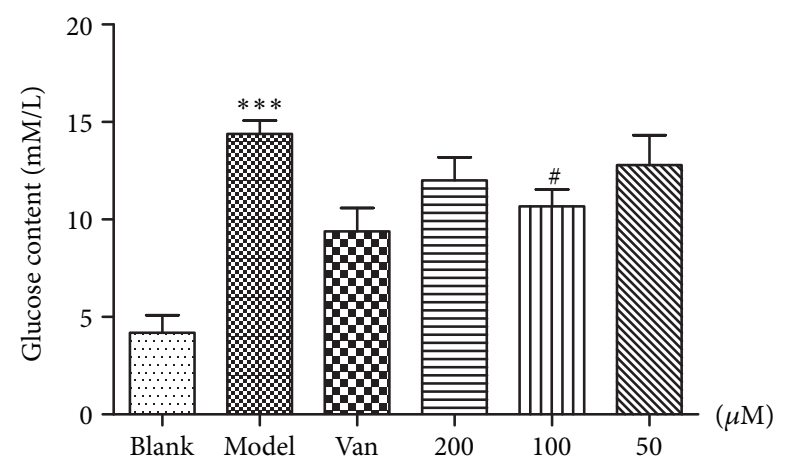

(c)

FIGURE 2: (a) Effects of phillyrin on glucose consumption in IR adipocytes, (b) effects of FEA on glucose consumption in IR adipocytes, and (c) effects of RFG on glucose consumption in IR adipocytes. Data are presented as means $\pm \mathrm{SD}, n=6 .{ }^{* * *} P<0.001$ versus blank group; ${ }^{\# \# \#} P$ $<0.001,{ }^{\# \#} P<0.01$, and ${ }^{\#} P<0.5$ versus model group. 
$100(P<0.01)$, and $50 \mu \mathrm{M}(P<0.5)$ (Figure $2(\mathrm{~b}))$. The glucose uptake of IR 3T3-L1 adipocytes was promoted by RFG at the concentrations of $100 \mu \mathrm{M}(P<0.5)$, but the effect was not as obvious as phillyrin (Figure 2(c)).

3.3. Effects of Phillyrin on the Expression of IRS-1 and Akt Phosphorylation Proteins. According to the results of adipocyte glucose depletion, phillyrin was selected to investigate the mechanism of improving IR. The effect of phillyrin on the expression of proteins related to PI3K/Akt insulin signaling pathway was investigated. The results showed that phillyrin could significantly increase the protein expression of PI-3K, p-IRS-1, p-Akt, and GLUT4 protein compared with the model group (Figure 3 ). And phillyrin could significantly promote p-Akt and p-IRS-1 and increase the expression of PI-3K and GLUT4 protein at the concentration of $200 \mu \mathrm{M}$ compared with other concentrations.

\section{Discussion}

As a Traditional Chinese Medicine, F. suspensa is the main raw material for Yinqiao detoxification granule, Shuanghuanglian oral liquid, Qingrejiedu oral liquid, Shuanghuanglian powder injection, and Liancao detoxification oral liquid $[28,29]$. Previous researches indicated that F. suspensa had an improvement effect on diabetic complications such as hypertriglyceridemia $[30,31]$. It is speculated that F. suspensa is closely related to the treatment of diabetes, and there is no research on $F$. suspensa improving insulin resistance and its potential mechanism. Therefore, the pharmacological effects of F. suspensa on hypoglycemia were investigated in this paper.

Adipocytes are one of the main target cells of insulin, which not only play a crucial role in energy balance, but also act as cytokines secreted by endocrine organs and regulating systemic metabolism [7]. Therefore, this cell line is one of the commonly used cell lines for the study of insulin resistance in vitro, and adipose tissue has been recognized as a promising therapeutic target for drug development [32]. Preadipocyte 3T3-L1 is selected to explore the pharmacological activity of F. suspensa in improving insulin resistance. Dexamethasone (Dex), a glucocorticoid, activates the signaling pathway by inhibiting insulin, thus preventing the transfer of GLUT4, resulting in insulin resistance. Dexamethasone is often used as the model drug of insulin resistance at the cellular level [33]. Therefore, dexamethasone is selected as the model drug in our research. Vanadium is one of the essential trace elements in higher animals, and studies have found that vanadium produces insulin-like effects in many cells in vitro [34-36]. This is consistent with our research, and sodium orthovanadate is selected as a positive control drug.

PI3K/Akt signaling pathway is one of the pathways of insulin action, which is closely related to the role of IR. Insulin binds to its receptor and its substrate, causing phosphorylation of receptor tyrosine residues and exerting its hypoglycemic effect [37]. In our research, phillyrin could activate the protein of PI3K by increasing the phosphorylation expression of IRS-1 protein (Figure 4) [38, 39]. It has been reported that the absence of IRS-1 or phosphorylated IRS-1 in muscle tissue and adipose tissue is associated with a high risk of diabetes mellitus [40]. Akt is a downstream signaling molecule in the PI3K protein pathway and also a core protein in the PI3K pathway $[41,42]$. When Akt protein is activated, it can promote the transfer of GLUT4 from the nucleus to the cell membrane, so it plays a role of glucose transfer and reducing blood glucose. The results showed that phillyrin could significantly increase the expression of PI3K, p-IRS-1, and GLUT4 proteins at concentrations of 200 and $100 \mu \mathrm{M}$. Phillyrin, isolated from F. suspensa, is a kind of lignans which are natural phenolic compounds with excellent biological activities and have been widely used in medicine and food. In recent years, the pharmacological investigations of lignans have been widely concerned. There are many reports about the hypoglycemic effect of plant extracts, flavonoids, carbohydrates, and other natural products. However, there are few reports about lignans [43, 44]. Studies on the improvement of insulin resistance by lignans included aminophenol and phillyrin [45]. Aminophenol, a fat soluble and flaxseed lignan, was studied with mice induced by a high-fat diet. Phillyrin exerts a beneficial effect on adipocyte dysfunctions induced by tumor necrosis factor- $\alpha$ (TNF- $\alpha$ ). It indicated that phillyrin may play a role in improving inflammatory changes and insulin resistance in obese adipose tissue [46]. It is different from the mechanism with our research to improve insulin resistance. Therefore, it is the first time that it was reported that lignin compounds improve insulin resistance by the PI3K/Akt signaling pathway.

In summary, phillyrin in F. suspensa could improve insulin resistance through adipocyte glucose uptake and active PI3K/Akt insulin signaling pathway.

\section{Conclusion}

Phillyrin in F. suspensa can promote glucose uptake in insulin resistance 3T3-L1 adipocyte. The mechanism may be exerted through activation of PI3K/Akt signaling pathway.

\section{Data Availability}

The data used to support the findings of this study are included within the article.

\section{Conflicts of Interest}

The authors declare that they have no conflicts of interest.

\section{Authors' Contributions}

Xiaoqing Xu, Fatma S. A. Saadeldeen, and Wenyi Kang conceived and designed the experiments. Xiaoqing Xu, Fatma S. A. Saadeldeen, and Zhenhua Liu performed the experiments. Jinfeng Wei and Yingying Zhao made substantial contributions to interpretation of data. Xiaoqing $\mathrm{Xu}$ and Zhenhua Liu wrote the first draft of the manuscript. Jinfeng Wei, Hui-Min David Wang, and Wenyi Kang revised the draft 

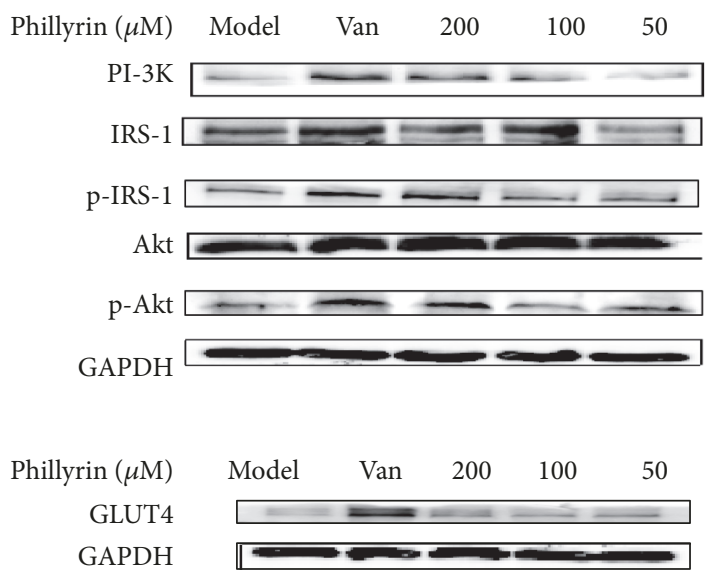

(a)
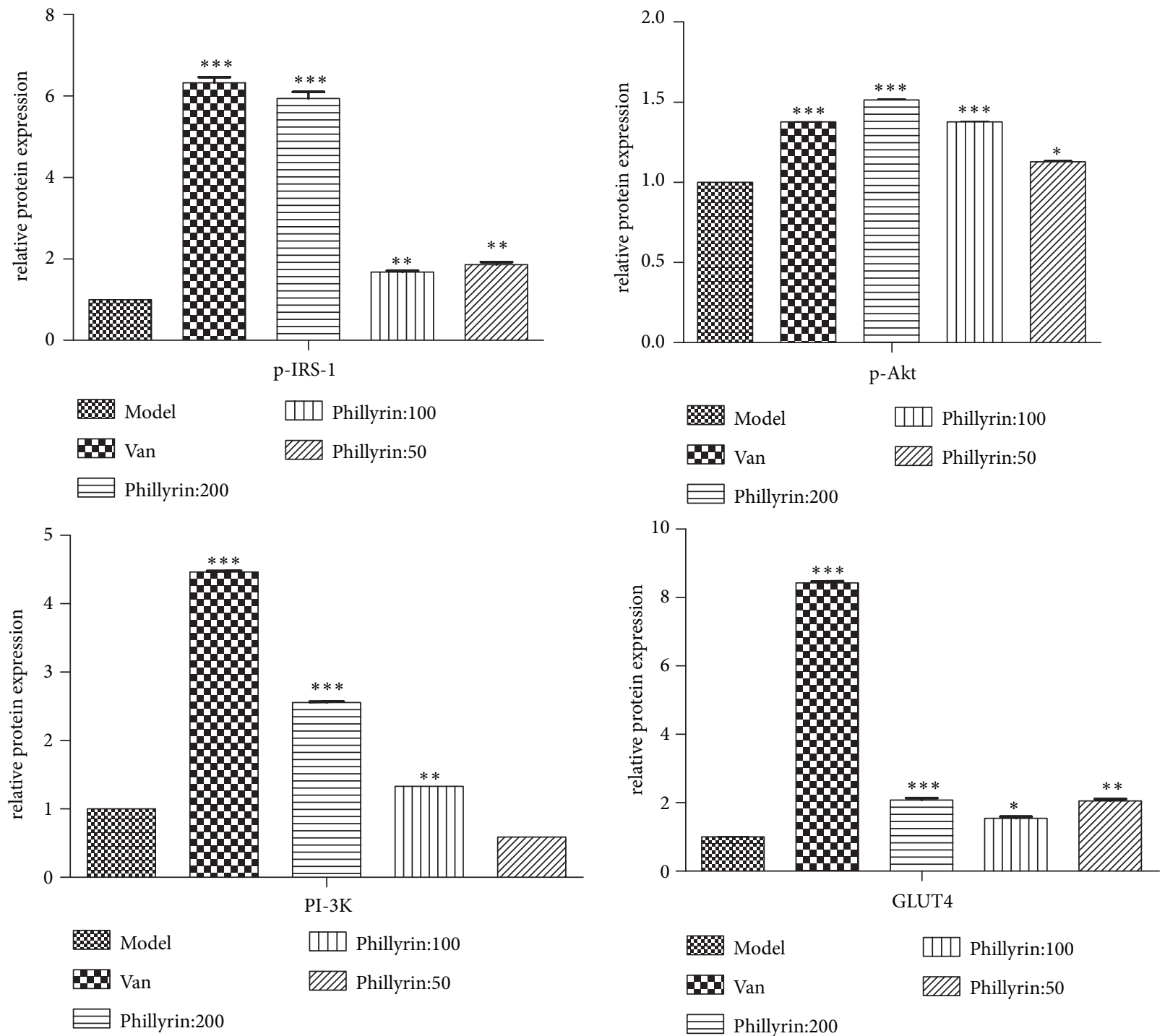

\& Model $\square$ Phillyrin:100

Dan

WIA Phillyrin:50

(b)

FIGURE 3: Western blot analysis of protein expression. (a) Effects of phillyrin on protein expression levels of PI-3K, IRS-1, p-IRS-1, Akt, p-Akt, GAPDH, and GLUT4 in IR 3T3-L1 adipocytes. (b) Gray value analysis of corresponding protein. Data are presented as means \pm SD, $n=6$. The experiments were repeated three times. ${ }^{* * *} P<0.001$, ${ }^{* *} P<0.1$, and ${ }^{*} P<0.5$ versus model group. 


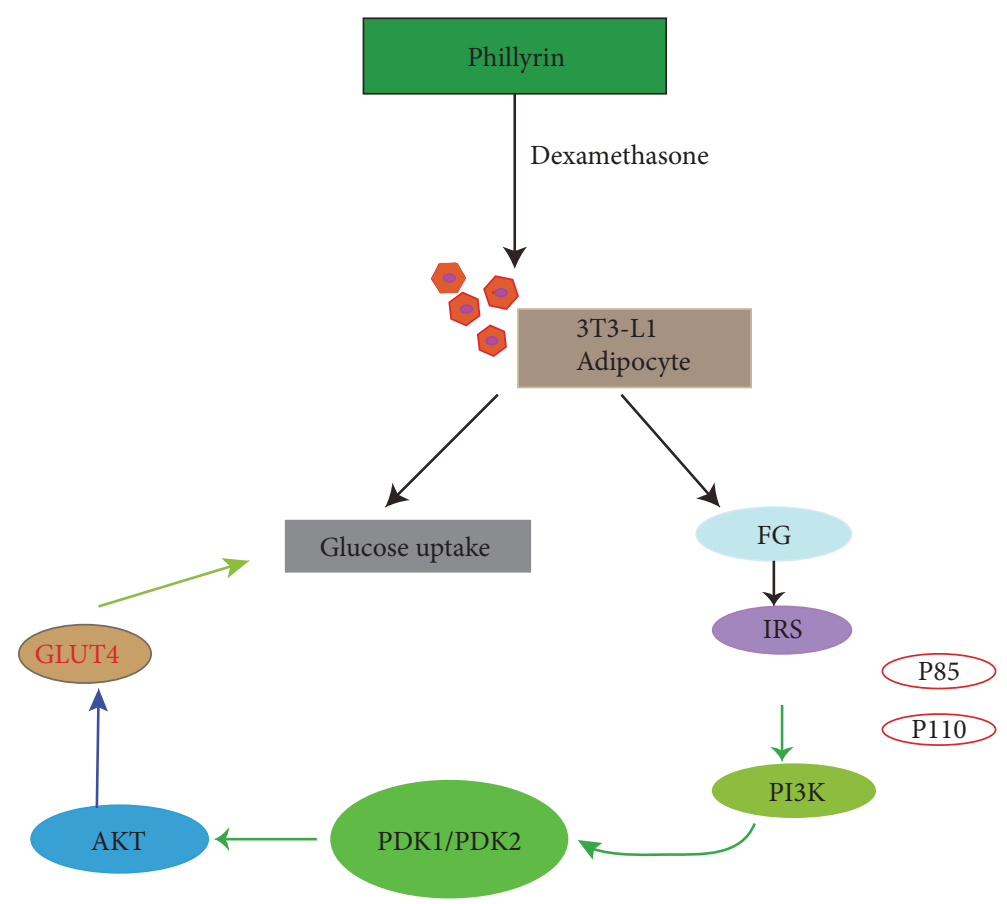

FIGURE 4: The mechanism of phillyrin to improve the insulin resistance.

and approved the version submitted. Xiaoqing Xu and Fatma S. A. Saadeldeen contributed equally.

\section{Acknowledgments}

This work was supported by Key Project in Science and Technology of Henan Province (182102110473 and 182102410083) and Natural Science Fund of Henan Province (162300410038).

\section{References}

[1] S. Zhu, F. Sun, W. Li et al., "Apelin stimulates glucose uptake through the PI3K/Akt pathway and improves insulin resistance in 3T3-L1 adipocytes," Molecular and Cellular Biochemistry, vol. 353, no. 1-2, pp. 305-313, 2011.

[2] C. Weyer, C. Bogardus, D. M. Mott, and R. E. Pratley, "The natural history of insulin secretory dysfunction and insulin resistance in the pathogenesis of type 2 diabetes mellitus," The Journal of Clinical Investigation, vol. 104, no. 6, pp. 787-794, 1999.

[3] J. H. Pang, Y. Zhou, and Z. J. Wang, “Type 2 diabetes and insulin resistance," Hebei Medicine, vol. 26, no. 4, pp. 292-293, 2004.

[4] D. F. Li, B. Yang, H. D. Yang et al., "The relationship between serum resistin and serum lipids, obesity and insulin resistance in patients with metabolic syndrome," Chinese Journal of Clinical Medicine, vol. 12, no. 2, pp. 206-208, 2005.

[5] M. J. Thomson, M. G. Williams, and S. C. Frost, "Development of insulin resistance in 3T3-L1 adipocytes," The Journal of Biological Chemistry, vol. 272, no. 12, pp. 7759-7764, 1997.

[6] K. Falk Petersen and G. I. Shulman, "New insights into the pathogenesis of insulin resistance in humans using magnetic resonance spectroscopy" Obesity, vol. 14, no. 1, pp. 34S-40S, 2006.

[7] B. J. Goldstein, "Insulin resistance as the core defect in type 2 diabetes mellitus," American Journal of Cardiology, vol. 90, no. 5, pp. 3-10, 2002.

[8] Y. Gao, M. Zhang, T. Wu, M. Xu, H. Cai, and Z. Zhang, "Effects of D-pinitol on insulin resistance through the PI3K/Akt signaling pathway in type 2 diabetes mellitus rats," Journal of Agricultural and Food Chemistry, vol. 63, no. 26, pp. 6019-6026, 2015.

[9] S. Schinner, W. A. Scherbaum, S. R. Bornstein, and A. Barthel, "Molecular mechanisms of insulin resistance," Diabetic Medicine, vol. 22, no. 6, pp. 674-682, 2005.

[10] S. Guo, "Insulin signaling, resistance, and metabolic syndrome: insights from mouse models into disease mechanisms," Journal of Endocrinology, vol. 220, no. 2, pp. T1-T23, 2014.

[11] M. L. Woodruff, A. Rajala, G. L. Fain, and R. V. S. Rajala, "Effect of knocking down the insulin receptor on mouse rod responses," Scientific Reports, vol. 5, 2015.

[12] F. Alghamdi, M. Guo, S. Abdulkhalek, N. Crawford, S. R. Amith, and M. R. Szewczuk, "A novel insulin receptor-signaling platform and its link to insulin resistance and type 2 diabetes," Cellular Signalling, vol. 26, no. 6, pp. 1355-1368, 2014.

[13] M. Chi, Y. Ye, X. D. Zhang, and J. Chen, "Insulin induces drug resistance in melanoma through activation of the PI3K/Akt pathway," Drug Design, Development and Therapy, vol. 8, pp. 255-262, 2014.

[14] D. F. Li, B. Yang, H. D. Yang et al., "The relationship between serum resistin and serum lipids, obesity and insulin resistance in patients with metabolic syndrome," Journal of Chinese Clinical Medicine, vol. 12, no. 2, 2004. 
[15] C. Nevado, A. M. Valverde, and M. Benito, "Role of insulin receptor in the regulation of glucose uptake in neonatal hepatocytes," Endocrinology, vol. 147, no. 8, pp. 3709-3718, 2006.

[16] Y. Terauchi, “Insulin receptor substrate (IRS)," Japanese Journal of Clinical Medicine, vol. 63, no. 8, pp. 548-550, 2005.

[17] J. S. Bogan and H. F. Lodish, "Two compartments for insulinstimulated exocytosis in 3T3-L1 adipocytes defined by endogenous ACRP30 and GLUT4," The Journal of Cell Biology, vol. 146, no. 3, pp. 609-620, 1999.

[18] S. Rea and D. E. James, "Moving GLUT4: the biogenesis and trafficking of GLUT4 storage vesicles," Diabetes, vol. 46, no. 11, pp. 1667-1677, 1997.

[19] E. J. Gallagher, Y. Fierz, A. Vijayakumar, N. Haddad, S. Yakar, and D. Leroith, "Inhibiting PI3K reduces mammary tumor growth and induces hyperglycemia in a mouse model of insulin resistance and hyperinsulinemia," Oncogene, vol. 31, no. 27, pp. 3213-3222, 2012.

[20] V. Patki, J. Buxton, A. Chawla et al., "Insulin action on GLUT4 traffic visualized in single 3T3-L1 adipocytes by using ultra-fast microscopy," Molecular Biology of the Cell (MBoC), vol. 12, no. 1, pp. 129-141, 2001.

[21] X.-L. Piao, M. H. Jang, J. Cui, and X. Piao, "Lignans from the fruits of Forsythia suspensa," Bioorganic \& Medicinal Chemistry Letters, vol. 18, no. 6, pp. 1980-1984, 2008.

[22] T. Lu, X. L. Piao, Q. Zhang et al., "Protective effects of Forsythia suspensa extract against oxidative stress induced by diquat in rats," Food \& Chemical Toxicology An International Journal Published for the British Industrial Biological Research Association, vol. 48, no. 2, pp. 764-770, 2010.

[23] J. Bao, R. DIng, L. Zou et al., "Forsythiae Fructus Inhibits B16 Melanoma Growth Involving MAPKs/Nrf2/HO-1 Mediated Anti-Oxidation and Anti-Inflammation," American Journal of Chinese Medicine, vol. 44, no. 5, pp. 1043-1061, 2016.

[24] M. B. Máximo, A. C. de Mendonça, V. R. Santos, L. C. Figueiredo, M. Feres, and P. M. Duarte, "Short-term clinical and microbiological evaluations of peri-implant diseases before and after mechanical anti-infective therapies," Clinical Oral Implants Research, vol. 20, no. 1, pp. 99-108, 2009.

[25] S. H. Han, Y. F. Wang, and J. X. Zhang, "Anti-endotoxin and immunoregulating effect of antiphlogistic tablet with forsythia fruit," Tianjin Journal of Traditional Chinese Medicine, 2004.

[26] Y.-H. Li, F.-J. Zheng, Y. Huang, X.-G. Zhong, and M.-Z. Guo, "Synergistic anti-inflammatory effect of Radix Platycodon in combination with herbs for cleaning-heat and detoxification and its mechanism," Chinese Journal of Integrative Medicine, vol. 19, no. 1, pp. 29-35, 2013.

[27] H.-B. Xing, H.-M. Pan, Y. Fang, X.-Y. Zhou, Q. Pan, and D. Li, "Construction of a tumor cell-targeting non-viral gene delivery vector with polyethylenimine modified with RGD sequencecontaining peptide," Oncology Letters, vol. 7, no. 2, pp. 487-492, 2014.

[28] M. M. A. Rahman, P. M. Dewick, D. E. Jackson, and J. A. Lucas, "Lignans of Forsythia intermedia," Phytochemistry, vol. 29, no. 6, pp. 1971-1980, 1990.

[29] M. Wang, L. Tao, and H. Xu, "Chinese herbal medicines as a source of molecules with anti-enterovirus 71 activity," Chinese Medicine, vol. 11, no. 1, p. 2, 2016.

[30] W. Kang and J. Wang, "In vitro antioxidant properties and in vivo lowering blood lipid of Forsythia suspense leaves," Medicinal Chemistry Research, vol. 19, no. 7, pp. 617-628, 2010.
[31] S. L. Abbate and J. D. Brunzell, "Pathophysiology of hyperlipidemia in diabetes mellitus," Journal of Cardiovascular Pharmacology, vol. 16, pp. S1-S7, 1990.

[32] A. E. Brodie, V. A. Manning, K. R. Ferguson, D. E. Jewell, and H. Ching Yuan, "Conjugated linoleic acid inhibits differentiation of pre- and post- confluent 3T3-L1 preadipocytes but inhibits cell proliferation only in preconfluent cells," Journal of Nutrition, vol. 129, no. 3, pp. 602-606, 1999.

[33] T. Ramasarma and F. L. Crane, "Does vanadium play a role in cellular regulation?” Current Topics in Cellular Regulation, vol. 20, no. C, pp. 247-301, 1981.

[34] C. Halleux, M. Takahashi, M. Delporte et al., "Secretion of adiponectin and regulation of apM1 gene expression in human visceral adipose tissue," Biochemical and Biophysical Research Communications, vol. 288, no. 5, pp. 1102-1107, 2011.

[35] B. R. Nechan, L. B. Nanninga, L. B. Nechay et al., "Role of Vanadium in biology," Federation Proceedings, vol. 45, pp. 123132,1986

[36] Lyonett, Martz, and Martin, "Lemploitherapeuti que dederives du Vanadium. La Presse Medi Cale," Journal of Clinical Investigation, pp. 191-192, 1899.

[37] N. Houstis, E. D. Rosen, and E. S. Lander, "Reactive oxygen species have a causal role in multiple forms of insulin resistance," Nature, vol. 440, no. 7086, pp. 944-948, 2006.

[38] C. W. Tsai, K. L. Liu, Y. R. Lin et al., "The mechanisms of carnosic acid attenuates tumor necrosis factor- $\alpha$-mediated inflammation and insulin resistance in 3T3-L1 adipocytes," Molecular Nutrition \& Food Research, vol. 58, no. 4, pp. 654664, 2014.

[39] C. Liou, S. Wu, L. Chen, K. Yeh, C. Chen, and W. Huang, "Acacetin from Traditionally Used Saussurea involucrata Kar. et Kir. Suppressed Adipogenesis in 3T3-L1 Adipocytes and Attenuated Lipid Accumulation in Obese Mice," Frontiers in Pharmacology, vol. 8, pp. 589-600, 2017.

[40] S. George, J. J. Rochford, C. Wolfrum et al., "A family with severe insulin resistance and diabetes due to a mutation in AKT2," Science, vol. 304, no. 5675, pp. 1325-1328, 2004.

[41] R. S. Garofalo, S. J. Orena, K. Rafidi et al., "Severe diabetes, agedependent loss of adipose tissue, and mild growth deficiency in mice lacking Akt2/PKB $\beta$," The Journal of Clinical Investigation, vol. 112, no. 2, pp. 197-208, 2003.

[42] H. Cho, J. Mu, J. K. Kim et al., "Insulin resistance and a diabetes mellitus-like syndrome in mice lacking the protein kinase Akt2 (PKB beta)," Science, vol. 292, no. 5522, pp. 1728-1731, 2001.

[43] A. Soumyanath, "Traditional medicines for modern times: antidiabetic plants," Economic Botany, vol. 336, 2006.

[44] R. Irchhaiya, A. Kumar, A. Yadav, and atal, "Metabolites in plants and its classification," World Journal Pharmacy and Pharmaceutical Science, vol. 4, no. 1, pp. 287-305, 2015.

[45] J. Sun, Y. Tang, X. Yu et al., "Flaxseed lignans alleviate high fat diet-induced hepatic steatosis and insulin resistance in mice: Potential involvement of AMP-activated protein kinase," Journal of Functional Foods, vol. 24, pp. 482-491, 2016.

[46] P. Kong, L. Zhang, Y. Guo, Y. Lu, and D. Lin, "Phillyrin, a natural Lignan, attenuates tumor necrosis factor $\alpha$-mediated insulin resistance and lipolytic acceleration in 3T3-L1 adipocytes," Planta Medica, vol. 80, no. 11, pp. 880-886, 2014. 

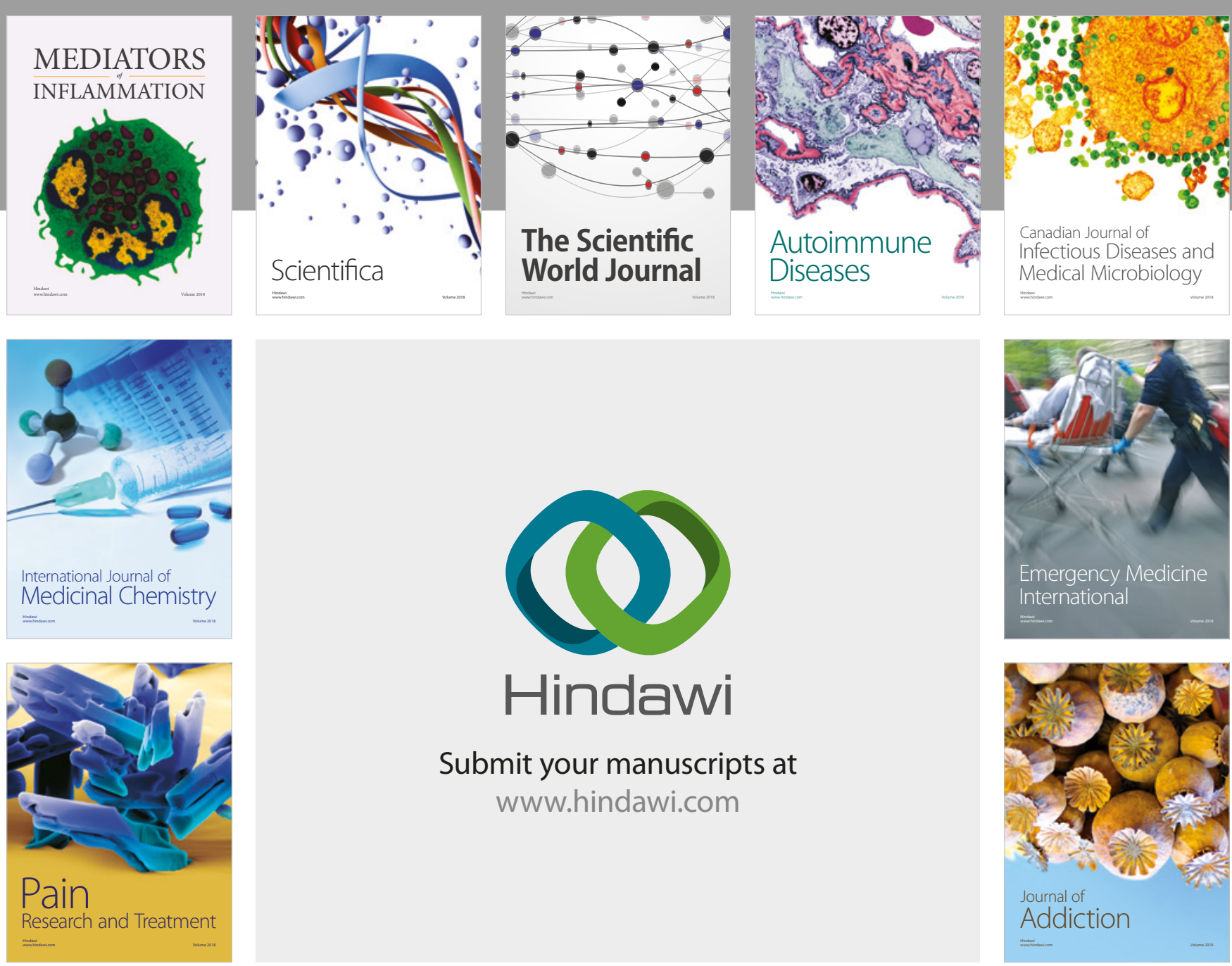

Canadian Journal of
Infectious Diseases and Medical Microbiology

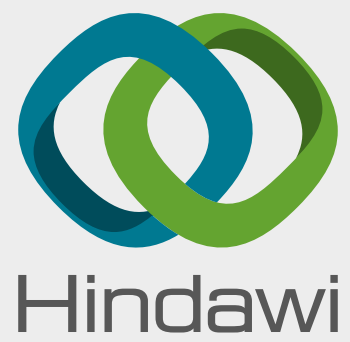

Submit your manuscripts at

www.hindawi.com
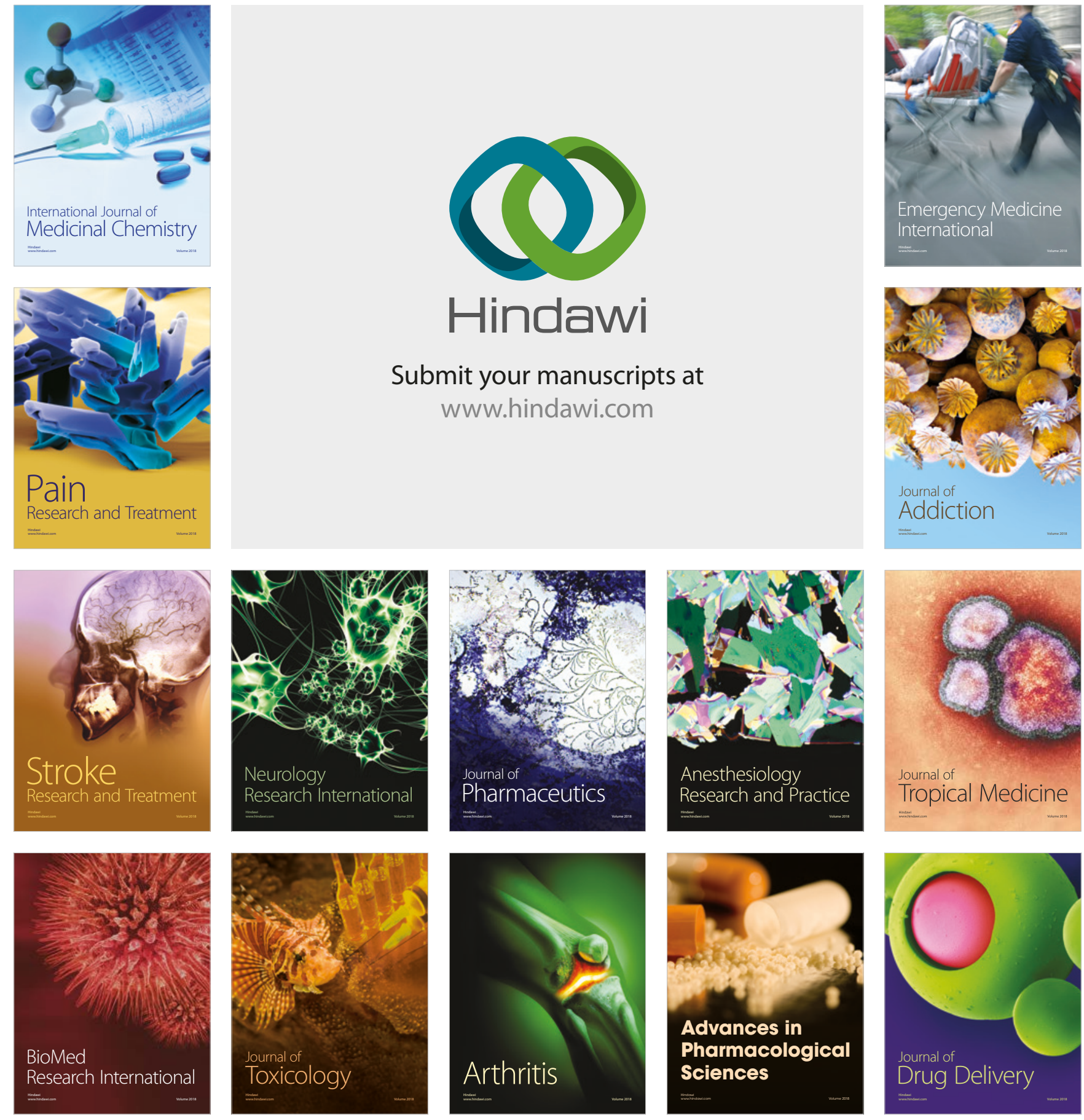